\title{
A função da psicanálise e o trabalho do psicanalista nos Serviços Residenciais Terapêuticos*
}

\author{
Ana Cristina Figueiredo \\ Ana Paola Frare
}

Este artigo apresenta os Serviços Residenciais Terapêuticos como dispositivos essenciais à consolidação da reforma psiquiátrica no Brasil, e propõe uma abordagem clínica a partir da psicanálise. A função principal do psicanalista seria transmitir aos cuidadores um modo de lidar com os moradores nas situações cotidianas na casa e na rua não reproduzindo a postura tutelar característica da lógica manicomial. As principais indicações são sustentar um saber-nãosaber como estratégia clínica e fazer valer os recursos subjetivos dos moradores como meios de manejar a convivência.

Palavras-chave: Serviços Residenciais Terapêuticos, psicanálise, reforma psiquiátrica, sujeito

* Este artigo foi elaborado a partir do projeto preliminar de pesquisa de doutoramento de Ana Paola Frare para o Programa de Pós-graduação em Psicanálise da Universidade Estadual do Rio de Janeiro, em parceria com a orientadora Ana Cristina Figueiredo. 


\section{Introdução}

A loucura como metáfora do "não sentido" sempre revela as contradições dos discursos que pretendem aprisionar sua plasticidade com soluções rápidas e eficazes, lançando desafios e apontando que as políticas de saúde necessitam o tempo todo de um novo olhar, um novo saber.

As tentativas de humanização e democratização dos espaços hospitalares que ocorreram na Europa e nos Estados Unidos no contexto do pós-guerra, bem como a criação de centros de atendimento extra-hospitalares contemporâneos a esse movimento, são um exemplo de como vêm se constituindo as apostas de promover um atendimento que dê continência à experiência da loucura sem ter como foco somente a hospitalização de longa permanência. A Itália é, indubitavelmente, um marco nesse processo de reconstrução da forma de atendimento e concepção de tratamento. Tendo como foco a desconstrução do aparato manicomial e a crítica ao aprisionamento da doença mental como objeto da psiquiatria, a desinstitucionalização evidencia uma estratégia de superação do modelo excludente, ao mesmo tempo em que propõe um rompimento com a prerrogativa médica sobre a loucura.

Notoriamente influenciado pelo modelo italiano da psiquiatria democrática, o processo de Reforma Psiquiátrica em curso há algumas décadas no Brasil, ${ }^{1}$ conta com avanços importantes no tocante à assistência e ao cumprimento da agenda de desinstitucionalização no país. Com a proposta explícita de lançar novos pressupostos para o manejo da loucura com a quebra do paradigma do modelo hospitalocêntrico, dispositivos diversos têm sido construídos para dar sustentabilidade ao novo projeto de atenção ao chamado "portador de transtorno mental", com base na concepção da reabilitação psicossocial, recuperação da autonomia e da contratualidade social.

Ancorados nesses pressupostos, os chamados "novos dispositivos" fomentam um novo arranjo de saberes e práticas, tais como os Centros de Atenção Psicossocial (CAPS), Hospitais-dia, Centros de Convivência, Serviços

1. Adoto aqui a concepção de Amarante (1995) que remete a gênese da Reforma Psiquiátrica Brasileira contemporânea à reconstrução democrática que impulsionou o movimento de luta antimanicomial, dos trabalhadores de saúde mental e diversas entidades ligadas à saúde, em grande parte fruto do trabalho de Franco Basaglia na década de 1980.

Rev. Latinoam. Psicopat. Fund., São Paulo, v. 11, n. 1, p. 82-96, março 2008 
Residenciais Terapêuticos, ${ }^{2}$ entre outros, se apresentam como estratégia política para desmonte do aparato manicomial, oferecendo uma alternativa tanto ao acolhimento social que impelia pacientes à permanência hospitalar, como ao acolhimento clínico de casos que, em geral, não necessitam estar em espaços restritivos para serem tratados.

O Serviço Residencial Terapêutico (SRT) é reconhecidamente uma das maiores apostas estratégicas da Reforma Psiquiátrica. De acordo com Santos (2006), esse serviço, além de oferecer uma resposta à cronificação e à exclusão social, também se constitui como "dispositivo de cuidado que aborda a parte mais difícil da Reforma Psiquiátrica, uma vez que enfrenta problemáticas do "estar em" e do "habitar" não somente uma casa, mas também a cidade daqueles que tiveram intensificada sua condição de "sofrimento psíquico grave" por muitos anos de internação" (p. 163).

Atualmente com cerca de 2.200 beneficiários, o SRT é um serviço que gera debates de todas as ordens. A criação deste dispositivo traz em sua gênese o legado deixado pelos anos em que o modelo hospitalocêntrico imperou, já que em sua maioria os usuários que são encaminhados para esse dispositivo têm em sua história a marca do abandono familiar e perda de vínculos durante os anos de internação. Por outro lado, pode ser pensado como uma resposta à questão do acolhimento desses pacientes que não sustentam uma moradia sem assistência, e que até então eram conduzidos a leitos hospitalares e lá permaneciam, em grande parte por sua condição social (Delgado, 2006). Apesar de inúmeras experiências terem sido levadas a cabo desde a década de 1980, somente com a norma de 2000 (portaria 106) ${ }^{3}$ que a denominação "serviço residencial terapêutico" ganha os contornos que impulsionaram sua função junto à desinstitucionalização. Dentre os marcadores deste dispositivo, estão a ênfase na função de modalidade substitutiva de internação psiquiátrica, sua localização exclusivamente alijada do espaço das unidades hospitalares e inseridas dentro da comunidade. Se por um lado a concepção desse serviço prioriza a instituição de uma casa, afastando-se da lógica hospitalar que pressupõe atitudes prescritivas e o controle da subjetividade, por outro, dá suporte a uma série de questões que requer uma

2. Esses são os dispositivos que estão regulamentados pela legislação atual. Vale ressaltar que há sempre outras denominações correntes para esses novos dispositivos de acordo com a história de cada serviço e/ou localidade. Porém, o que interessa destacar é o fato de terem sido criados e estarem a serviço do processo de Reforma Psiquiátrica.

3. Portaria que versa sobre a constituição do Serviço Residencial Terapêutico, seu desenho estrutural (número de moradores, localização preferencial do serviço entre outros) e as formas de financiamento que dão sustentabilidade ao projeto. 
organização institucional, que contempla por exemplo, um técnico de referência, cuidadores, supervisão, entre outros. Assim, entre a "casa" e o "dispositivo", vai sendo traçada a teia em que o serviço se enreda. ${ }^{4}$

Não há dúvida que o modelo de atenção psicossocial como paradigma da Reforma Psiquiátrica Brasileira cumpre o seu papel de devolver ao louco um lugar no tecido social. Certamente ao entrar em uma residência terapêutica, essa sensação é ratificada. Ainda mais se esse olhar que atesta a melhoria da qualidade de vida dos usuários já mirou um hospício em pleno funcionamento.

As condições de habitação, o leque ampliado de possibilidades de relações sociais, a inserção em atividades ofertadas pela vida na cidade, são alguns dos exemplos de como o cotidiano dos usuários dos serviços residenciais terapêuticos se transforma após a exoneração do hospício como local de permanência ininterrupta.

"Uma casa é uma casa" é o imperativo proclamado afirmando que "o lar não deve servir de residência à pedagogia, à poderosa tradição do tratamento moral, ao assistencialismo, nem à escuta hiperestésica. Mas tampouco o abandono" (Delgado, 2006, p. 30).

Em seu texto "Qual instituição para o sujeito psicótico?” Zenoni (2000) argumenta sobre a diferença entre a função social da instituição e a função terapêutica, sendo que "essa distinção só é possível se colocamos no ponto de partida, a clínica” (p. 29). Trata-se de reconhecer que há duas práticas distintas para então conjugar as possibilidades a partir da afirmação das diferenças. De acordo com Viganò (2000), "isso nos leva a inverter a relação entre o sujeito e as instituições: não é o sujeito que deve respeitar as instituições, mas é a instituição que só será respeitada se tiver vontade de dar ao sujeito uma representação, um lugar no vínculo social" (p. 30). Desse modo, o lugar de saber ocupado pelos propósitos da instituição deve ser repensado, para dar lugar a uma escuta do sujeito que coloque o ouvinte no lugar de "aluno da psicose" (Zenoni, 2000).

Convidados a abdicar do hospital como moradia, a conviver com outras pessoas que muitas vezes não conhecem e a incluir a cidade como algo rotineiro em sua existência, os moradores se vêem diante de situações, crises, questões, e toda a ordem de acontecimentos que desmontam qualquer abordagem mais prescritiva de condutas.

No cotidiano do serviço, as soluções advêm a partir de determinados atos. Acontecem coisas o tempo todo: os vizinhos reclamam de algo que o morador

4. Sobre essa aparente dicotomia, Cavalcanti et al. (2006) demonstram o quanto é possível tomar dois termos contraditórios em dialética e transformar em potência a escuta de um a um, surpreendendo-se a cada encontro.

Rev. Latinoam. Psicopat. Fund., São Paulo, v. 11, n. 1, p. 82-96, março 2008 
disse, fez ou disse que iria fazer; o cuidador tem que apartar um litígio que foi "às vias de fato"; uma crise é desencadeada a partir de uma recusa qualquer; alguém reclama de ter que avisar quando sai em função de todas as vezes que se perdeu na cidade e não encontrou o caminho de casa.

Refletir sobre todos esses movimentos e principalmente dividir essa responsabilidade com os cuidadores e com os próprios moradores é o grande desafio dos técnicos de referência. Em princípio, o saber deve ser colocado do lado do sujeito, assegurando que "aquilo que não cessa de não se inscrever" não tentará ser domado pedagogicamente, mas contornado a partir de uma borda que daria certa continência a essa experiência peculiar.

A partir do reconhecimento dos benefícios da transição manicômio/casa deve-se perguntar se o terapêutico que nomeia a residência está localizado nela ou na própria vida na cidade. Delgado (2006) aponta para o paradoxo de quanto menos "clínica" a residência se propuser, mais eficaz será a meta de conquista de autonomia. "Quanto menos 'clínica' ou 'terapêutica', mais eficaz como clínica" (p. 30). A dilatada definição sobre o que se entende como "clínica" dentro desse espaço indica que as possibilidades são inúmeras.

Entre os propósitos de um dispositivo que visa a busca de autonomia e inclusão social, emolduram-se alguns que ora se aproximam, ora se afastam da ética da psicanálise.

A transformação da realidade objetiva é por certo essencial, mas não suficiente. "A ausência de opressão, a inclusão e o resgate da cidadania perdida devem estar intrinsecamente ligados a uma dimensão clínica permanentemente presente na relação de cada morador com os cuidadores, a fim de que haja, efetivamente, uma cidadania a ser promovida" (Santos, 2006, p. 165).

A ética da psicanálise não contempla a idéia de "clínica" tal como a denunciada em algumas práticas excludentes, já que dispara seu olhar a partir da possibilidade de emergência de um sujeito, em oposição a um objeto da ciência. ${ }^{5}$ Se a resposta frente à possibilidade de não disciplinar é colocar a clínica a serviço do sujeito e não da tutela, não basta afirmar que há uma clínica possível e necessária nesse lugar. De acordo com Rinaldi (2005), “é nesse novo campo (...) dos dispositivos de atenção psicossocial trazidos pela reforma psiquiátrica, que os psicanalistas procuram inserir o dispositivo analítico, com sua ética própria, por intermédio de uma clínica que visa o sujeito" (p. 88).

5. Recorro à discussão de Fink (1998) que demonstra como o discurso da ciência sutura o sujeito, isto é, não considera o sujeito falante como sujeito, excluindo-o do campo da ciência positivista, enquanto a psicanálise aplica-se justamente à divisão do sujeito. 
Nesse fôlego de desinstitucionalizar, criar aparatos para receber os pacientes, e ainda lançar um outro entendimento ao fenômeno da loucura, a reflexão sobre a prática clínica se faz mister. Primeiro porque há de se localizar qual o papel dessa prática e suas implicações, para que os fundamentos da psicanálise sejam colocados a serviço da ética da psicanálise, não recaindo em uso de "categorias" que se aproximam da psicanálise, mas a serviço de uma "psicanálise falsa". ${ }^{6}$ Segundo, porque não podemos abdicar de nosso ofício de acolher os sujeitos que deixam o manicômio e realmente precisam de assistência.

E quando o local onde somos convocados a trabalhar deveria ser o lugar próprio do morar? Como bem recorta Santos (2006): "Mas o que faz a clínica em uma moradia? Seu local de exercício não é um dispositivo de tratamento? O que está sendo nomeado como clínico não equivale ao que o campo da Reforma Psiquiátrica chama de cuidado?” (p. 165). A autora responde a essa questão afirmando que no SRT há uma dimensão clínica que não se afirma como tratamento, e destaca a psicanálise como o alicerce dessa tarefa.

A experiência desenvolvida por uma das autoras ${ }^{7}$ no programa de SRTs em Paracambi-RJ a partir da intervenção na Casa de Saúde Dr. Eiras serve como plataforma para a discussão mais geral do tema. Certamente é necessário cartografar a importância desse hospício para localizar as interposições do SRT e da cidade, tarefa que foge ao escopo deste artigo. Com o total de 21 residências, no Serviço Residencial de Paracambi, o chamado Técnico de Referência é referência permanente de pelo menos uma casa, bem como da equipe que a sustenta (cuidadores) e dos usuários que ali moram. É o técnico que conduz as questões com os vizinhos, que faz o intermédio da utilização do dinheiro, da necessidade de consultas clínicas, psiquiátricas, e auxilia a inserção do morador na cidade, apresentando possibilidades, gerenciando demandas, supervisionando a equipe e manejando (clinicamente) os acontecimentos na residência. $O$ trabalho envolve todas as etapas desde o processo de desospitalização até a recepção dos casos na Residência Terapêutica, consolidando a desinstitucionalização como passo necessário e estratégico da Reforma Psiquiátrica e principal foco da intervenção. É sobre esse cotidiano, seus impasses, suas possibilidades e impossibilidades que deve se dar a reflexão sobre os operadores da psicanálise e a função do psicanalista.

6. Lacan (2003) traça a distinção entre a psicanálise verdadeira e a falsa, alertando que uma tentativa de psicanálise, que se afasta dos princípios da mesma pode ser um bem que leva ao pior (p. 173).

7. Como técnica de referência de duas residências terapêuticas em Paracambi-RJ, Ana Paola Frare referencia 14 moradores e supervisiona uma equipe de cuidadores constituída de nove integrantes.

Rev. Latinoam. Psicopat. Fund., São Paulo, v. 11, n. 1, p. 82-96, março 2008 


\section{O trabalho do psicanalista (e a função da psicanálise) no SRT}

"Uma casa é uma casa", frase de uma moradora que expressa oposição a uma suposta tutela, traz a dimensão imaginária do discurso que "minha casa" é o avesso do hospício e, contraditoriamente, é o lugar onde se pode fazer "o que quiser". Trazer a dimensão simbólica disso é convocar o sujeito a repensar seu enunciado, pois sem dúvida "uma casa é uma casa" e, como todas, possui regras de convivência e normas a serem respeitadas. O limite se impõe de um outro lugar que não a tutela. As normas só interessam se subjetivadas, e a imposição "educativa" de uma regra se desfaz frente à imposição de um querer do Outro. Desta feita, é na filigrana do entendimento de regras que os operadores da psicanálise apontam para uma outra direção: não se trata simplesmente de adequar o morador às regras ou adaptá-lo ao convívio com os outros. "A regra que rege a vida coletiva é a regra que se aplica inicialmente ao Outro" (Viganò, 2000, p. 23). A posição dos operadores desse convívio não é então a de "fazer valer as regras" mas presentificar um Outro que é ele mesmo submetido à lei. É trazer essa dimensão, esvaziando o querer caprichoso do Outro e responsabilizando sempre o sujeito. Não se trata somente do pragmatismo da vida na cidade e das imputações decorrentes do não cumprimento de contratos sociais. Certamente esse aspecto está incluído, mas não subtrai a responsabilidade do sujeito por sua posição.

Figueiredo (2007) aclara a distinção entre responsabilidade e tutela, afirmando que

... o sujeito é responsável por sua existência (ou ex-sistência) e como tal "responde" seja como for, ao que lhe é apresentado, oferecido ou mesmo imposto, seja no surto ou na estabilização. Não há como desresponsabilizá-lo nesse ponto retirando-lhe qualquer possibilidade de resposta. A responsabilidade civil ou jurídica deve ser auferida a partir dessa responsabilidade de existência inicial. (p. 4)

Nesse sentido, muitas vezes é necessário que se responda negativamente a uma demanda, outras vezes que se coloque um ponto de basta. Na convivência com os outros há regras, e também cabe apresentá-las, só não cabe operar moralmente com quem não executa a contratualidade do modo esperado, não cabe creditar imaginariamente a uma adaptação o fato de as normas serem seguidas ou não, pois restaurar um laço do sujeito com o Outro é a possibilidade de subjetivação das regras. "Procura-se, junto ao sujeito, demonstrar a presença não de uma regra, mas de um sintoma, de um sintoma como presença do significante do Outro que ele traz em si” (Laurent, 2000, p. 173). 
Se, muitas vezes, o pedagógico e o terapêutico são elementos presentes em uma psicanálise, na clínica do "só depois", não é possível partir somente das práticas efetuadas em um dispositivo para determinar se ali há possibilidade de superar uma lógica "ortopédica". É necessário olhar para os efeitos das práticas e recolocar a questão: é possível que o SRT favoreça a emergência do sujeito? Ou, de outro modo: é possível que um dispositivo concebido a partir de uma lógica (psicossocial) comporte um outro discurso (psicanalítico) para dar sustentação a uma clínica que tem uma outra visada?

Certamente as cores que dão o tom a esse quadro devem ser matizadas nos contextos em que são produzidas. De acordo com Laurent (1999), o analista-cidadão não é antagônico às novas formas de assistência em saúde mental "formas democráticas, anti-normativas e irredutíveis a causalidade ideal" (p. 19), porém o que chamamos de reabilitação não pode se reduzir a um trabalho que desconsidere a dimensão do sintoma, que tome esse como análogo à patologia, sob o risco de propor uma reabilitação como exclusão da clínica (Viganò, 2000). Desse modo, entre a patologização que toma o sujeito como objeto, e a adequação do sujeito às normas sociais, existem outras possibilidades de manejar a loucura na cidade.

Para a psicanálise, a adaptação comportamental está colocada em detrimento da noção de sujeito já que, como bem discorre Fink (1998), “a análise não é pragmática em seus objetivos, se pragmatismo significa estar de acordo com as normas e realidades sociais, econômicas e políticas" (p. 179).

Se, por um lado, a atenção psicossocial consegue atender à questão do "sujeito social" devolvendo-lhe a tão convocada, mas pouco discutida "cidadania", por outro é necessário delimitar em que termos o trato com a loucura nesses dispositivos pode favorecer o aparecimento de um sujeito nos termos da psicanálise. Mas de que sujeito estamos falando? De que sujeito se trata quando pensamos na atenção psicossocial e qual a diferença para o sujeito da psicanálise? Novamente a relação dialética entre cidadão e sujeito vem apontar uma possibilidade de debate.

Para a psicanálise, o sujeito está assujeitado pela linguagem que intervém a partir do campo do Outro. Não se tem acesso à sua "realidade" senão através da linguagem e, portanto, é da posição que o sujeito toma diante do Outro que ali reconhecemos o que há de subjetivo e particular. Como aponta Figueiredo (2005), é necessário ter em conta que o sujeito é antes de tudo um efeito da intervenção do Outro, e que deve ser considerado em sua relação com o gozo, seja o gozo do sujeito em sua forma de enlaçamento ou desenlaçamento social ou o gozo do Outro que o invade de forma avassaladora. "O ato da palavra não é originário e não basta que nos disponhamos à escuta para que ali exista um sujeito que nos fale. (...) Lacan diz claramente que aquilo que a psicanálise 
produziu de revolucionário não se refere ao sujeito, mas ao gozo" (Viganò, 2006, p. 28). Isso aponta para o fato de que não basta afirmar que dentro dos novos dispositivos há uma escuta, ou "alguém" que escuta, para que ali se favoreça a emergência de um sujeito. A "escuta” psicanalítica parte de uma posição ética (ética do desejo por diferença à ética do bem) e não se alinha a qualquer intento do que é "bom" para o paciente. É uma clínica que opera sobre o real, que considera as modalidades de gozo, que se coloca como aprendiz em relação à psicose, que se dispõe a secretariá-la na difícil operação de recobrir o real, que não compreende a psicose como déficit, mas como posição subjetiva.

$\mathrm{Na}$ perspectiva de Zenoni (2000), a chamada "segunda clínica" de Lacan ou clínica "continuísta" é convocada para uma interlocução com os dispositivos psicossociais e incluindo aí os SRT, principalmente como possibilidade de trabalho a partir do real dos acontecimentos cotidianos sobre os quais somos convocados a pensar e operar. Mas o que a psicanálise pode nos trazer como meio de intervenção nesse espaço? Se não é possível regredir completamente do saber do mestre, é necessário então substituí-lo por um debate democrático, que leve a equipe a uma tomada de decisão. Viganò (2000) afirma que "qualquer reforma no campo da saúde mental será tal se somente vier a tocar o real da doença mental, estabelecido como limite da subversão subjetiva" (p. 43), colocando assim a possibilidade de efetivação de uma mudança subjetiva de objeto a sujeito: "só assim, também, o psicótico poderá entrar no circuito do discurso social, a condição que o sujeito vem remetido sobre suas bases como criação no real, a partir do jogo dos significantes, da ordem simbólica" (p. 44). Portanto, a inserção da prática psicanalítica em dispositivos de saúde mental se apresenta como profícua nos intentos de colocar o saber do lado do sujeito, sem, no entanto, equiparar essa posição com a chamada "autonomia". ${ }^{8}$

É possível inferir que o inusitado da resposta pensada para os SRT é justamente tentar lidar com o real da loucura no lócus onde ela opera: a cidade. A máxima de Lacan "Não recuar diante da psicose" indica não somente não recuar diante da estrutura psicótica, mas sim não recuar diante do real da loucura e, conseqüentemente, da clínica como operador daquilo que insiste, dando endereço à loucura: empregar-se ao lado do morador no esforço de barrar os excessos do Outro, auxiliá-lo naquilo que permite que se oriente na ordem do simbólico, para que construa formas de inserção no tecido social. A equipe de cuidadores freqüentemente ocupa esse lugar de mediador, que sustenta essas inserções e que intervém no real dos acontecimentos. Nesse sentido o trabalho de supervisão

8. Figueiredo (2007, p. 42) aponta o limite entre autonomia e sujeição, afirmando que são relativizadas até onde cada um responde a partir de sua divisão radical. 
junto aos cuidadores é fundamental para autorizar essa clínica do e no acontecimento, para fazer suportar o "não saber" e inventar a cada vez.

Em um conhecido texto sobre SRT, "Uma casa para Ribas", encontramos uma discussão que aponta para essa acepção. Ao propor a construção do caso de Ribas, a ação da equipe emerge como ponto pontencializador do debate: "viuse, nessa ocasião, fazer valer um ponto fundamental de uma prática feita por muitos: a equipe só se autoriza a operar a partir do que não sabe" (Macedo et al., 2003, p. 94).

Essa afirmação nos leva a duas vertentes de análise junto à equipe de cuidadores: 1) uma possibilidade de trabalhar a partir das direções da chamada "prática entre vários ou muitos", 9 2) o aspecto "leigo"10 dos cuidadores.

Já temos de saída uma dimensão desse cuidado que é a possibilidade de uma identificação imaginária que, dentro de certos balizadores, pode ser salutar, pois não se trata de um técnico que lança um olhar sobre um doente, mas de um sujeito que cuida de outro. Entretanto, o sujeito que cuida tem que estar advertido para se abster de colocar o seu sintoma nessa relação, para poder ocupar um lugar vazio que permite uma intervenção efetiva. Neste ponto a supervisão vai operar como transmissão, para que o que está sendo apontado como "leigo" não se torne homólogo à "ignorância" ou recusa de saber sobre o outro. A justificativa para a não especialização dos cuidadores é sustentada na tentativa de garantir a quebra da medicalização, patologização e psicologização dos comportamentos dos usuários do serviço a partir de um olhar "não técnico". Certamente esse pleito, que pressupõe em sua gênese que o "técnico" é aquele que sabe sobre o sujeito, nos vale também em um outro sentido: os cuidadores "sabem que não sabem" e, curiosamente, podem deslizar mais facilmente para um registro de "saber não saber". Assim, são convocados a construir junto com o morador uma forma de lidar com a sua particularidade. Nesse percurso, há muitas angústias, dúvidas, incertezas e, logo, tentativas de todas as ordens são empenhadas.

O trabalho de escuta dessa equipe deve suportar a suspensão da moral de regulação normativa para deixar-se cair em um encontro com o estranho, até o

9. Prática muito difundida e implementada principalmente em instituições para crianças autistas e jovens psicóticos. Autores como Di Ciaccia, Laurent, Zenoni, Viganò são algumas das principais referências para fundamentar essa ação que consiste basicamente em traçar uma direção comum à equipe para cada caso, priorizar o contorno do excesso de gozo e a manifestação do sujeito com seus próprios recursos, e proceder à construção coletiva do caso a partir dos elementos dados pelo sujeito.

10. Sempre se privilegiam na contratação desses trabalhadores pessoas que não tenham experiência com a psiquiatria, principalmente em hospitais. 
ponto em que supõe um saber ao sujeito. "Coisas" acontecem, e é na radical inversão de uma lógica que vê ali a "desrazão" ou um "objeto de intervenção", que a inventividade dos cuidadores começa a operar como ato clínico. ${ }^{11}$ No acontecimento toma-se, sem nenhum pudor, a palavra "ao pé da letra", permitindo a suspensão de um saber engessado sobre o outro e o trabalho sobre os efeitos das intervenções. Nesse sentido, as intervenções dos cuidadores não se encerram somente em "atender" o que o morador está trazendo como demanda, mas junto com ele encontrar soluções para suas questões. Um exemplo dessas intervenções pode ser retirado de um caso. Um morador, bastante invadido, aponta para o "nada" e, com muito sofrimento, pergunta repetidamente a todos os moradores: "eu estou morto?". Nenhuma resposta da cuidadora o fazia parar: "sim... não..., por que você acha isso..." etc. Em dado momento ela pergunta ao morador quem queria saber. O mesmo aponta "para o nada" e diz: "ele". A cuidadora, nesse momento, grita (com certa teatralidade) para o mesmo "nada" que o morador apontou e diz: "ele morreu! ele morreu!". O morador dá um suspiro de alívio e conclui "enganamos ele". Ao que a cuidadora responde: "Ótimo. Vamos jantar então?”.

Como diz Zenoni (2000), "é a psicose que nos ensina sobre a estrutura e que nos ensina sobre as soluções que ela mesma encontra para fazer face a uma falta central do próprio simbólico. É na escola da psicose que nos colocamos para aprender como praticar" (p. 19). Nesse sentido, é através do desejo decidido de cada um que se pode construir uma posição de "alunos da psicose", de secretariar o sujeito. Na supervisão, as intervenções que visam fazer operar a norma no um a um, em vez de um padrão normativo generalizado, aparecem na invenção. Aí se dá a transmissão desse fazer orientado pela psicanálise que só pode operar a partir dos acontecimentos cotidianos em seus pequenos detalhes.

$\mathrm{Na}$ perspectiva da "prática entre vários" pressupomos, por exemplo, que o supervisor (ou coordenador terapêutico) abdique do poder que ocupa dentro da equipe, convocando todos os membros para a construção do caso que está em pauta. Não se trata somente de fazer vacilar uma suposta hierarquia, e sim fazer a desconstrução de um saber suposto ao supervisor para autorizar a própria equipe a sustentar "saber não saber". É também acentuar o que é diferente, o "estilo" de cada um dos técnicos que ali se apresentam para o sujeito, retirando o caráter imaginário de "igualdade" entre a equipe e promovendo uma operação

11. Figueiredo (2007, p. 44) conceitua ato clínico como "acontecimento que deve localizar, apontar e convocar o sujeito que ainda permanece 'oculto' no chamado paciente ou usuário, seja em sua apatia ou excesso como modos de gozo desregulado. O operador do ato clínico é a chave do trabalho marcado pela ética do desejo que constitui a experiência da psicanálise". 
com cada morador. Estas abordagens devem ser "feitas por todos" no sentido de que todos se colocariam na mesma posição de não saber (Di Ciaccia, 1999).

Baio (1999) localiza que a função da reunião de equipe não é tratar da equipe, mas que esta "possa se manter na posição de um Outro regulado, ou seja, de um Outro que sabe não saber" (p. 70). Nesse sentido, o supervisor não opera no discurso do analista (e esse mesmo não é aplicável ao sujeito psicótico), mas a partir do desejo do analista, que convoca a equipe a ocupar o lugar do Outro barrado, desprovido de um saber último. A equipe então deve sustentar o saber do lado do sujeito, e mediar a convivência a partir desse lugar. Desse modo, o primeiro ponto a ser colocado é o lugar do "ao menos um".

$\mathrm{Na}$ operação de grupos, freqüentemente ocorre uma "cola imaginária" no grupo que trabalha junto e que coloca o supervisor no lugar do mestre/senhor. Quando "ao menos um" faz a subtração desse lugar, estabelecendo a função do mais um num lugar de êxtimo, de garantia de trabalho, a operação se dá a partir da falta, vazio que promove um outro arranjo que desfaz essa cola imaginária.

$\mathrm{Na}$ nossa experiência, muitas vezes "estratégias de manejo" são combinadas na reunião de equipe a partir dos efeitos de alguma intervenção, intervenções estas que ocorrem dentro da casa, do supermercado, da praça, e que estão balizadas pela convocação do Outro barrado, apresentando regras de convivência que não podem ser recusadas, e subtraindo o valor moral de como alguém "deve se comportar" na cidade.

Desse modo, ao convocar a psicanálise para um espaço que pressupõe que o terapêutico de viver na cidade é esse encontro em si, que preconiza que a autonomia e a contratualidade sejam tomadas como axioma da subjetividade; torna-se necessário pensar em termos de "como" é possível que os operadores da psicanálise possam se constituir como política de tratamento, dando um desenho para o dispositivo que não o descaracterize em sua concepção, mas que ganhe contornos em que a emergência de um sujeito seja possível. E, mais do que isso, convocar a psicanálise é responsabilizar-se por esse fazer, para não recair em uma prática que se afasta de seus princípios e, conseqüentemente, de sua ética.

Nesses termos, o morar comporta não só as condições de habitação, mas todas as dimensões implicadas nos sentidos de "habitar" um lugar. Pensar em uma "casa" para acolher os pacientes é pensar além do "concreto" da casa, com todos os artifícios que ali são engendrados, para que o ambiente seja reconhecido como tal. Para além do "ambiente" da casa temos aí, enlaçadas ou não, as dimensões imaginárias, reais e simbólicas que evocam a possibilidade de se viver em uma casa e, conseqüentemente, de viver na cidade. E junto com Macedo (2003) sustentamos a casa como lugar de acolhimento do impossível de suportar, a equipe como um aparato que se mantém estrategicamente na postura de um

Rev. Latinoam. Psicopat. Fund., São Paulo, v. 11, n. 1, p. 82-96, março 2008 
saber-não-saber, e a supervisão como um método para adequar o regulamento ao caso e daí extrair uma direção.

\section{Referências}

Amarante, Paulo. A trajetória da reforma Psiquiátrica no Brasil. Rio de Janeiro: Ed. Fiocruz, 1995.

BAIO, Virginio. O ato a partir de muitos. Curinga/EBP, Belo Horizonte, n. 13, p. 66-73, set.1999.

Cavalcanti, Maria Tavares et al. Casa e/ou Serviço? O dilema das moradias assistidas e/ou Serviços Residenciais Terapêuticos no contexto da Reforma psiquiátrica brasileira. Cadernos IPUB, Rio de Janeiro, v. XII, n. 22, p. 83-91, nov-dez 2006.

Delgado, Pedro Gabriel. Instituir a desinstitucionalização: o papel das residências terapêuticas na Reforma brasileira. Cadernos IPUB, Rio de Janeiro, v. XII, n. 22, p. 1933, nov-dez 2006.

Di CiACCIA, Antonio. Da fundação por Um à prática feita por muitos. Revista Curinga/ EBP, Belo Horizonte, n. 13, p. 60-65, set.1999.

. A prática entre vários. In: Altoé, Sonia e Lima, Márcia Mello (Orgs.). Psicanálise, clínica e instituição. Rio de Janeiro: Rio Ambiciosos, 2005.

Figueiredo, Ana Cristina. Uma proposta de psicanálise para o trabalho em equipe na atenção psicossocial. Mental - Revista de Saúde Mental e Subjetividade da UNIPAC, Barbacena, ano III, n. 5, p. 43-55, nov.2005.

- A clínica da atenção psicossocial: uma proposta da psicanálise. ReIs FiLho, José Tiago e Franco, Vânia Carneiro (Orgs.). Aprendizes da clínica: novos fazeres psi. São Paulo: Casa do Psicólogo, 2007.

FINK, Bruce. O sujeito lacaniano - entre a linguagem e o gozo. Rio de Janeiro: Zahar, 1998; LACAN, Jacques. A psicanálise verdadeira, e a falsa. In: Outros escritos. Rio de Janeiro: Jorge Zahar, 2003.

Laurent, Eric. O analista cidadão. Curinga/EBP, Belo Horizonte, n. 13, p. 12-19, set.1999.

. Psicanálise e Saúde Mental: a prática feita por muitos. Curinga/EBP, Belo Horizonte, n. 14, abr.2000.

MACEDo, Lucíola Freitas et al. Uma casa para Ribas. Opção Lacaniana, Rio de Janeiro, n. 37, 2003.

Rev. Latinoam. Psicopat. Fund., São Paulo, v. 11, n. 1, p. 82-96, março 2008 
Miller, Jacques-Alain. Psicanálise Pura, Psicanálise Aplicada \& Psicoterapia. Revista Phenix EBP, Curitiba, n. 3, 2001.

RinALDI, Doris. Clínica e política: a direção do tratamento psicanalítico no campo da saúde mental. In: AltoÉ, Sonia e Lima, Márcia Mello (Orgs.). Psicanálise, clínica e instituição. Rio de Janeiro: Rio Ambiciosos, 2005.

SAntos, Kátia Wainstock. A experiência de um Serviço Residencial Terapêutico para adolescentes autistas e psicóticos. Cadernos IPUB, Rio de Janeiro, v. XII, n. 22, novdez. 2006.

Viganò, Carlo. A construção do caso clínico em saúde mental. Curinga/EBP, Belo Horizonte, n. 14, 2000.

. A palavra na Instituição. Mental - Revista de Saúde Mental e Subjetividade da UNIPAC, Barbacena, ano IV, n. 6, p. 27-32, jun.2006.

Zenoni, Alfredo. Psicanálise e instituição: a segunda clínica de Lacan. Belo Horizonte: Abrecampos, 2000.

\section{Resumos}

(La función del psicoanálisis y el trabajo del psicoanalista en los servicios residenciales terapéuticos)

Este artículo presenta los Servicios Residenciales Terapéuticos como dispositivos esenciales para la consolidación de la reforma psiquiátrica en Brasil y propone un abordaje clínico a partir del psicoanálisis. La función principal del psicoanalista es la de transmitir a los cuidadores un modo de lidiar con los residentes en las situaciones cotidianas, en la casa o en la calle, que no reproduzca la postura tutelar característica de la lógica del manicomio. Las principales indicaciones son sustentar un saber-nosaber como estrategia clínica y hacer valer los recursos subjetivos de los moradores como medios de manejar el convivir.

Palabras claves: Servicios Residenciales Terapéuticos, psicoanálisis, reforma psiquiátrica, sujeto

(La fonction de la psychanalyse et le travail du psychanalyste dans les services résidentiels thérapeutiques)

Cet article présente les Services Résidentiels Thérapeutiques comme des dispositifs essentiels pour la consolidation de la réforme psychiatrique au Brésil et propose une approche clinique à partir de la psychanalyse. La fonction principale du psychanalyste serait celle de transmettre aux soigneurs une façon de traiter les habitants soit chez eux, soit dans la rue qui ne reproduit pas la posture de tutelle caractéristique de la logique 
hospitalière. Les principales indications sont: soutenir un savoir-pas-savoir comme stratégie clinique et faire valoir les ressources subjectives des résidents comme moyens de négocier la cohabitation.

Mots clés: Services Résidentiels Thérapeutiques, psychanalyse, réforme psychiatrique, sujet

(The function of psychoanalysis and the work of the psychoanalyst in therapeutic residential services)

This article describes therapeutic residential services as essential practices for consolidating the psychiatric reform carried out in Brazil and puts forward a clinical approach based on psychoanalysis. From this point of view, the psychoanalyst's main function is to provide caregivers with ways of dealing with patients in everyday situations, either at home or outside, without reproducing the patronizing attitude typical of mental institutions. The main proposals are to sustain a certain unknowing knowledge as a clinical strategy and the use of the patients' subjective resources as ways of managing the experience of living together.

Key words: Therapeutic Residential Services, psychoanalysis, psychiatric reform, subject

Versão inicial recebida em fevereiro de 2008

Versão aprovada para publicação em fevereiro de 2008

\section{Ana Cristina Figueiredo}

Psicanalista; doutora em Saúde Coletiva pelo IMS/Universidade Estadual do Rio de Janeiro (Rio de Janeiro, RJ, Brasil); professora do Instituto de Psiquiatria IPUB/Universidade Federal do Rio de Janeiro (Rio de Janeiro, RJ, Brasil); professora colaboradora do Programa de Pós-graduação em Psicanálise da Universidade Estadual do Rio de Janeiro. Supervisora da rede de serviços de Saúde Mental - SMS-Rio. Membro da Associação Universitária de Pesquisa em Psicopatologia Fundamental (São Paulo, SP, Brasil).

Instituto de Psiquiatria IPUB/UFRJ

Av. Venceslau Brás 71 - fundos - Botafogo

22290-140 Rio de Janeiro, RJ, Brasil

ana.cfigueiredo@terra.com.br

\section{Ana Paola Frare}

Psicanalista. Mestre em Saúde Coletiva pelo IMS/Universidade Estadual do Rio de Janeiro (Rio de Janeiro, RJ, Brasil); doutoranda do Programa de Pós-graduação em Psicanálise da Universidade Estadual do Rio de Janeiro; Supervisora e técnica de referência de SRT no município de Paracambi, RJ, Brasil.

Instituto de Psiquiatria IPUB/UFRJ

Av. Venceslau Brás 71 - fundos - Botafogo

22290-140 Rio de Janeiro, RJ, Brasil

anapaolafrare30@gmail.com

Rev. Latinoam. Psicopat. Fund., São Paulo, v. 11, n. 1, p. 82-96, março 2008 